PRINT ISSN 1119-8362

Electronic ISSN 1119-8362
Full-text Available Online at https://www.ajol.info/index.php/jasem

http://ww.bioline.org.br/ja
J. Appl. Sci. Environ. Manage.

Vol. 25 (3) 401-406 March 2021

\title{
Design, Construct and Evaluation of a Single Row Hand-Pushed Mechanical Weed Control Machine
}

\author{
*SALEH, A; SULEIMAN, ML
}

\author{
Department of Agricultural and Bio-Resources Engineering, Ahmadu Bello University, P.M.B. 1044, Zaria, Nigeria \\ *Corresponding author, e-mail address: salehaminu@gmail.com; Tel: +234803 5774780
}

\begin{abstract}
Weed control is one of the major problems in crop and vegetable production in Nigeria. Most of the peasant farmers use manual weeders in their cultivation, a process that is costly, labour intensive and time consuming. The process does not also give the farmer adequate returns to enable him breakeven. It is, therefore, necessary to design a weeding equipment which minimize the human effort and provide efficient work output for the peasant farmer. This study focus on designing, construction and evaluation of a hand-pushed weed control machine that would eliminate the challenges being faced by the farmer in weeding. Materials selected to suit the construction of the weeder are durable and locally available, easily replaced if damaged and at affordable cost. They include mild steel $(3 \mathrm{~mm}, 5 \mathrm{~mm}), 30 \mathrm{~mm}$ circular (hollow) pipes, $10 \mathrm{~mm}$ diameter steel rod, and $40 \mathrm{~cm}$ pneumatic tyre. The developed weeding machine was evaluated in the experimental farm of IAR with impressive results. It works well in sandy loam soil of about $25.65 \%$ moisture content and requires less labour force compared to the manual hoe. It has about $84.7 \%$ weeding efficiency, $0.0129 \mathrm{ha} / \mathrm{hr}$ effective field capacity, $0.019 \mathrm{ha} / \mathrm{hr}$ theoretical field capacity and $68 \%$ field efficiency. The average cost of the weeding is $\mathrm{N} 21$, 000:00.
\end{abstract}

\section{DOI: https://dx.doi.org/10.4314/jasem.v25i3.14}

Copyright: Copyright $(0) 2021$ Saleh and Suleiman. This is an open access article distributed under the Creative Commons Attribution License (CCL), which permits unrestricted use, distribution, and reproduction in any medium, provided the original work is properly cited.

Dates: Received: 12 December 2020; Revised: 26 January 2021; Accepted: 12 February 2021

Keywords: Manual weeding, hand-pushed weeder, weeding efficiency, field efficiency

One of the major problems in crop and vegetable production in Nigeria is weed control. Weeds are plants growing where they are not wanted. They are probably the most ever-present class of crop pests and are responsible for marked losses in crop yields. They also deteriorates the quality of farm produce and hence reduce their market value. Weeds competes with the crops for nutrients, space, light and water. Numerous studies have documented negative effects of weed competition on crop yield. Results of such studies shows that crop losses measured under weedy conditions for maize was between $55-90 \%, 40-80$ $\%$ for sorghum, $40-60 \%$ for cowpea and $50-100 \%$ for rice, (Ishaya et al., 2007; Chikoye et al., 2004; Dadari and Mani, 2005). Management of weeds is, therefore, imperative for sustainable crop production and to ensure food security to the ever-increasing population. Weed management is a combination of the techniques of prevention, eradication and control to manage weeds in a crop, cropping system, or environment. Weed managers recognize that field's cropping history, grower's management objectives, available technology, financial resources, and a host of other factors must be combined to make good management decisions (Rana and Rana, 2016). Weeding could be done manually, mechanically, biologically or by means of agro-chemicals. Hand weeding is the predominant weed control practice on smallholder farms in Nigeria and most Sub-Saharan Africa (Vissoh et al., 2004). It is the oldest method and consists of hand-pulling, hand slashing and hoeing of weeds. Studies shows smallholder farmers spend 50 $70 \%$ of their total labour time in hand weeding (Chikoye et al., 2007; IFAD, 1998). Manuals weeding is constrained by none availability of hired labour during peak periods, drudgery, migration to urban areas and limited cash for hiring labour (Johnson, 1995 and Bisikwa et al., 1997). This necessitates use of mechanical means of weeding to eliminate the challenges associated with manual weeding; Yadav and Pund, 2007. Mechanical weed control, on the other hand, refers to any technique that involves use of farm equipment to control weeds. Implements used vary from simple hand tools to multiple tractor drawn implements; Rana and Rana, 2016. Most existing mechanical weed control machines are drawn by tractors. Peasant farmers who are in the majority today do not have access to credit facilities and cannot afford to buy or hire such weed control machines in order to enhance their farming capabilities. It, thus, becomes necessary to develop and construct a weed control equipment that could be affordable and require minimum human efforts for its motion, but could weed 
at a greater speed and efficiency, hence, the objective of this study.

\section{MATEIALS AND METHODS}

Materials to be used for the construction of the weeder are; $3 \mathrm{~mm}$ and $5 \mathrm{~mm}$ mild steel, $30 \mathrm{~mm}$ circular (hollow) pipes, $10 \mathrm{~mm}$ diameter steel rod, $10 \mathrm{~mm}$ bearings, $10 \mathrm{~mm}$ square rod, $17 \mathrm{~mm}$ bolt and nuts and $400 \mathrm{~mm}$ diameter pneumatic tyre that could be replaced with an iron wheel depending on soil type. The bases of choice for these materials were their durability and availability, ease of replacement if damaged and light in weight for safety and ease of transportation. Their cost is also affordable to a local fabricator and medium scale famer. In its construction, the weeder was made in such a way that it is easy to operate and maintain while the components could easily be dismantled for replacement and repairs. Traction on the wheels has also been considered for proper movement on different soil conditions. Other materials used were weighing scale, oven, soil sampler, measuring tape, steel rule and a stop watch.

Description of the Weeder: The components of the weeder consists a frame, wheel, tine cultivator, furrower and a weeding blade as shown in Figure 1, while the Orthographic view of the Single Row Hand-Pushed Mechanical Weed Control Machine is presented in Figure 2.

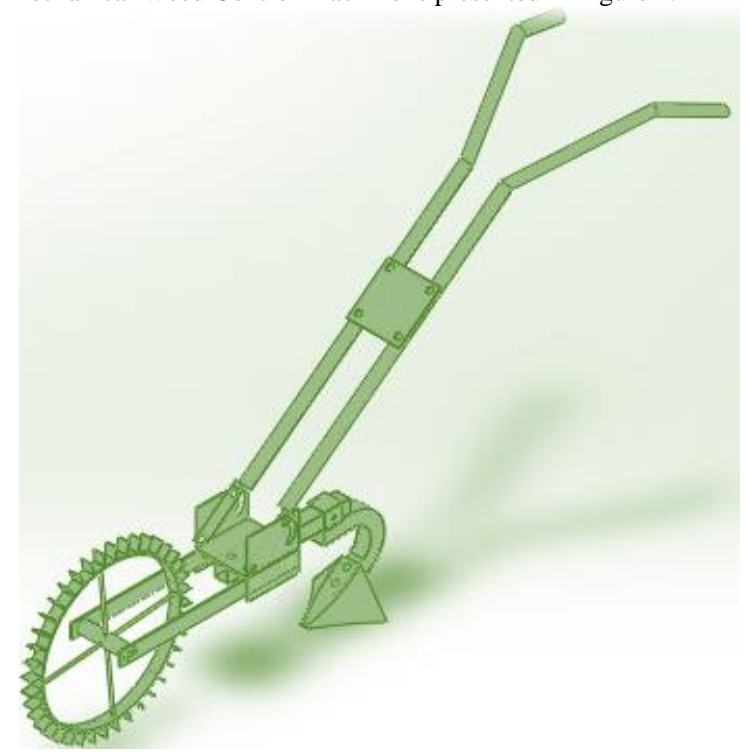

Fig 1: Pictorial View of the Developed Weeder 1

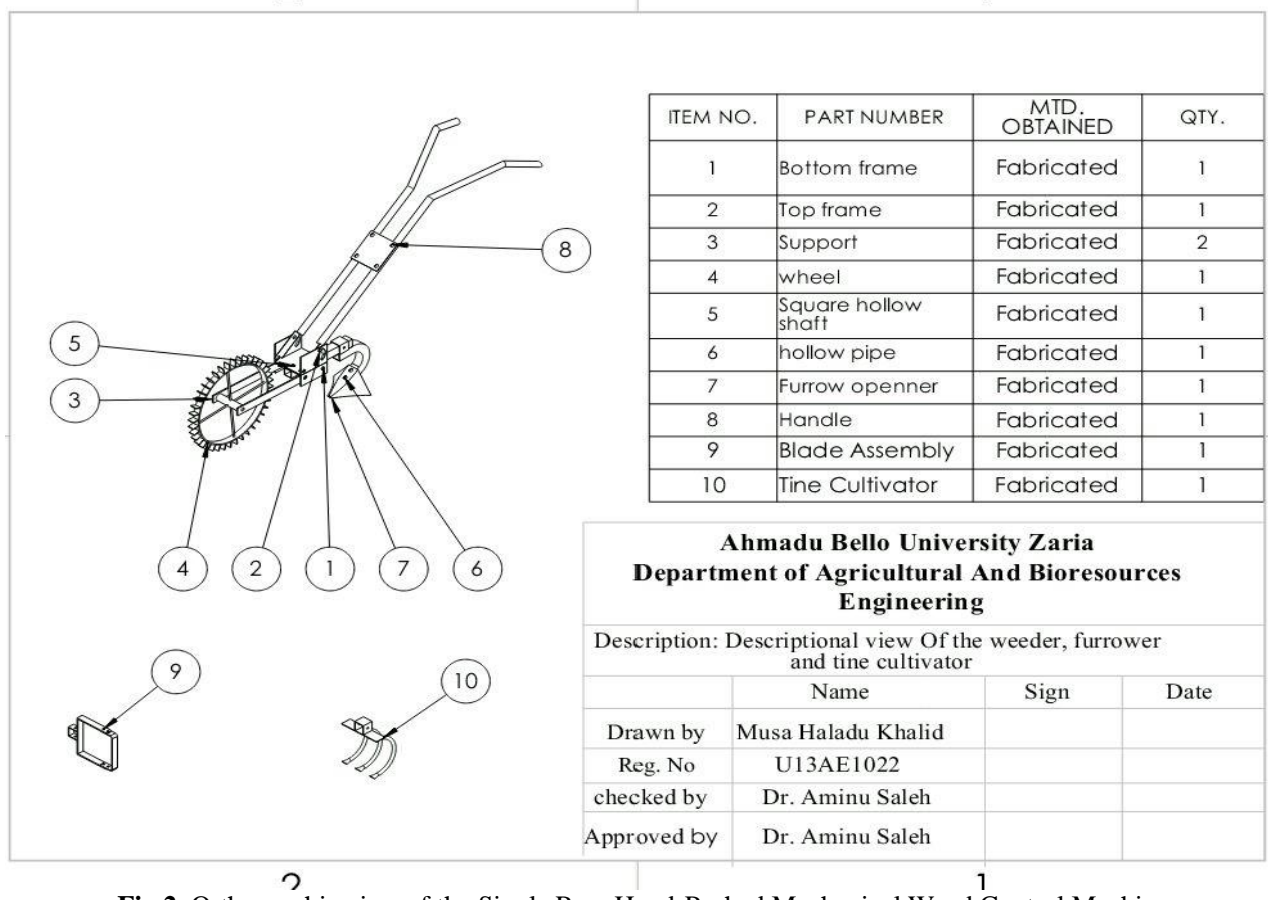

Fig 2. Orthographic view of the Single Row Hand-Pushed Mechanical Weed Control Machine

Frame - The frame is the skeletal/structural component on which all the components of the weeder were built, supported and attached. It was made from $3 \mathrm{~mm}$ mild steel rod. All the components mounted on it were attached with bolts and nuts for ease of transport and replacement of defective parts.
Wheel - The weeder has two different wheels; pneumatic (moulded and tubless) and steel wheels. Both are of the same diameter $(400 \mathrm{~mm})$ and are used depending on the type of soil.

Handle - The handle was constructed using $30 \mathrm{~mm}$ diameter circular (hollow) pipe. Ergornomic and 
anthropometric aspects were considered in such a way it suit variety of users. It was attached to the frame to control and direct the weeder on the field.

Tine cultivator - The tine cultivator was made from 10 $\mathrm{mm}$ diameter steel rods which were flattened at its base and supported at the top by a mild steel metal sheet. It was meant to work on a stony and rooted soils.

Furrower - The furrower was made from a $3 \mathrm{~mm}$ mild steel metal to form a typical sweep furrow of $18 \times 18$ $\mathrm{mm}$.

Weeding blade - The weeding blade which forms the integral part of the weeder was made from $5 \mathrm{~mm}$ mild steel plate. It's diamensions are $20 \times 20 \mathrm{~mm}$. It has a sharp blade which is used to cut, slice and pulverize the soil for effective weeding.

Experimental site: The study was conducted in the Department of Agricultural and Bio-Resources Engineering, Ahmadu Bello University, Zaria between March and December, 2019. While construction was done at the departmental workshop, the weeder was tested at the experimental farm of the Institure for Agricultural Research (IAR). The soil in the site is sandy loam.

Determination of the Weeder Performance: The performance parameters of the weeder such as weeding efficiency, plant damaged, effective field capacity, theoretical field capacity and field efficiency of weeder were determined and evaluated through the following expressions:

Weeding efficiency - This is the ratio of the numbers of weeds removed by the weeder to the number of weeds in a unit area before weeding and is expressed as a percentage. It was expressed using equation (1) as suggested by Madhusudhana (2015).

$$
\text { Weedingefficiency }(\%)=\frac{W_{1}-W_{2}}{W_{2}}
$$

Where: $W_{1}=$ Number of weeds counted per unit area before weeding operation, $W_{2}=$ Number of weeds counted in same unit area after weeding operation.

Plant damage - Plant damage is the ratio of the number of plants damaged after weeding operation to the number of plants before the weeding. It is expressed in percentage.

$$
\text { Plant Damage }(\%)=\left(1-\frac{q}{p}\right) \times 100
$$

Where: $p=$ Number of plants in a row before weeding, $\mathrm{q}=$ Number of plants in a row after weeding.
Effective field capacity - Effective field capacity is the actual average rate of coverage by the weeder based upon the total field time. It is a function of the rated width of the weeder, the percentage of rated width actually utilized, speed of the travel and the amount of field time lost during the operation. Effective field capacity is expressed in ha/h (Kepner $e t$ al., 1978).

$$
E F C=\frac{A}{T_{p+T} T_{i}}
$$

Where: $\mathrm{EFC}=$ Effective field capacity, ha/h; $\mathrm{A}=$ Actual area covered, ha, $T_{p}=$ Productive time, $\mathrm{h}, T_{i}=$ Non-productive time, $\mathrm{h}$

Theoretical field capacity - Theoretical field capacity of the weeder is the rate of field coverage obtained if the weeder were performing its function $100 \%$ of the time at the rated forward speed and always covered $100 \%$ of its rated width. It is expressed in ha/h (Kepner et al., 1978):

$$
T F C=\frac{W \times S}{10}
$$

Where: TFC $=$ Theoretical field capacity, ha/h; $\mathrm{w}=$ Width of cut, $\mathrm{m} ; \mathrm{s}=$ Speed of operation, $\mathrm{Km} / \mathrm{h}$

Field efficiency - Field efficiency is the ratio of effective field capacity to the theoretical field capacity, expressed as percentage. It includes the effect of time lost in the field and failure to utilize the full width of the weeder.

$$
\eta_{e}=\left(\frac{\mathrm{EFC}}{\mathrm{TFC}}\right) \times 100
$$

Where: $\eta_{e}=$ Field efficiency, $\%$; EFC $=$ Effective field capacity, ha/h; TFC $=$ Theoretical field capacity, $\mathrm{ha} / \mathrm{h}$

Bulk density of soil - The bulk density of soil was determined by core cutter method. The core sampler of the soil of known volume was collected and weighed. The soil bulk density was mathematically determined as the ratio of the mass of soil to volume of soil:

$$
\rho=\frac{M}{V}
$$

Where: $\rho=$ Bulk density, $\mathrm{g} / \mathrm{cm}^{3} ; \mathrm{M}=$ Mass of the soil, $\mathrm{g} ; \mathrm{V}=$ Volume of the soil, $\mathrm{cm}^{3}$

Moisture content of soil - The moisture content of the soil was determined by oven drying method. Soil samples were taken from three different points on the field. The samples which weight $400 \mathrm{~g}, 398 \mathrm{~g}$ and 405 $\mathrm{g}$ were kept in the thermostatically controlled oven at 
a temperature of $105^{\circ} \mathrm{C}$ for 24 hours. The dried soil was again weighed and the moisture content is determined as:

$$
M_{c}=\frac{W_{w}-W_{d}}{W_{d}}
$$

Where: $M_{c}=$ Moisture content, $(\% \mathrm{db}) ; W_{w}=$ weight of moist soil, $\mathrm{g} ; W_{d}=$ weight of dry soil, $\mathrm{g}$

Effective working depth: The depth of cut of the weeder with different blades was measured in the field by measuring the depth of soil layer tilled by the blade in a row. The depth of the weeding was measured by measuring rule in different rows at different places. Average of five observations was taken as depth of weeding and expressed in $\mathrm{cm}$.

Effective working width: The width of cut of the machine with different blades was measured in the field by observing the strip of soil and weeds cut in a row.

\section{RESULTS AND DISCUSSION}

The average bulk density of the soil (sandy loam) collected from three different points of the field was determined to be $1.21 \mathrm{~g} / \mathrm{cm}$. The average moisture content of the area was found to be $25.65 \%$ (Table 1). Results obtained (Table 2) shows that the working widths of the three implements determined from three different attachments (tine cultivator, weeding blade and furrower) were $3.85 \mathrm{~cm}, 4.11 \mathrm{~cm}$ and $6.87 \mathrm{~cm}$ respectively. This shows that the furrower has a wider coverage than the other attachments, hence less time taken to weed an area. Similarly, the average effective working depth for three attachments were $20 \mathrm{~cm}$, $19.30 \mathrm{~cm}$ and $17.09 \mathrm{~cm}$ respectively (Table 3). This indicated that the tine cultivator which penetrates deeper into the soil has the tendency of uprooting stubborn weeds and those that has deeper tap roots. Deeper seed bed also means tendency to allow more water and air circulation, hence provides more conducive environment for crop growth.

Table 1: Bulk Density and Moisture Content of the Soil

\begin{tabular}{|c|c|c|c|c|c|}
\hline Samples & \multicolumn{2}{|c|}{$\begin{array}{l}\text { Weight of } \\
\text { wet (g) }\end{array}$} & $\begin{array}{l}\text { Weight of } \\
\operatorname{dry}(\mathrm{g})\end{array}$ & $\begin{array}{l}\text { Moisture content } \\
\text { on dry basis }(\%)\end{array}$ & $\begin{array}{l}\text { Bulk density } \\
\left(\mathrm{g} / \mathrm{cm}^{3}\right)\end{array}$ \\
\hline $\bar{A}$ & \multicolumn{2}{|c|}{400} & 317.0 & 26.18 & 1.22 \\
\hline B & \multicolumn{2}{|l|}{398} & 320.0 & 24.38 & 1.20 \\
\hline C & \multicolumn{2}{|l|}{405} & 320.4 & 26.40 & 1.21 \\
\hline Average & \multicolumn{2}{|l|}{401} & 319.0 & 25.65 & 1.21 \\
\hline \multicolumn{6}{|c|}{ Table 2: Working widths of the Weeder } \\
\hline \multirow{2}{*}{\multicolumn{2}{|c|}{ Area/Implement }} & \multicolumn{2}{|c|}{ Tin cultivator } & Weeding Blade & Furrower \\
\hline & & \multicolumn{2}{|c|}{$(\mathrm{cm})$} & & \\
\hline \multicolumn{2}{|l|}{ A1 } & \multicolumn{2}{|c|}{20} & 19.4 & 17.3 \\
\hline \multicolumn{2}{|l|}{ A2 } & \multicolumn{2}{|c|}{20} & 19.2 & 17.10 \\
\hline \multicolumn{2}{|l|}{ A3 } & \multicolumn{2}{|c|}{20} & 19.4 & 17.21 \\
\hline \multicolumn{2}{|l|}{ Average } & \multicolumn{2}{|c|}{20} & 19.3 & 17.09 \\
\hline \multicolumn{6}{|c|}{ Table 3: Effective Working Depth } \\
\hline \multirow{2}{*}{\multicolumn{2}{|c|}{ Area/Implement }} & \multicolumn{2}{|c|}{ Tine cultivator } & Weeding Blade & Furrower \\
\hline & & \multicolumn{2}{|c|}{$(\mathrm{cm})$} & & \\
\hline \multicolumn{2}{|l|}{ A1 } & \multicolumn{2}{|c|}{3.84} & 4.11 & 6.32 \\
\hline \multicolumn{2}{|l|}{ A2 } & \multicolumn{2}{|c|}{4.10} & 4.00 & 7.10 \\
\hline \multicolumn{2}{|l|}{ A3 } & \multicolumn{2}{|c|}{3.60} & 4.23 & 7.21 \\
\hline \multicolumn{2}{|l|}{ Average } & \multicolumn{2}{|c|}{3.85} & 4.11 & 6.87 \\
\hline
\end{tabular}

The test for the weeding efficiency was carried out on the field size of $2 \times 1 \mathrm{~m}$. The average weed population was 600 before weeding operation while weeds left after the exercise was an average of 7 for both attachments. The weeding efficiency was computed using Equation (1) given as:

$$
A W E(\%)=\frac{600-7}{7}=84.7 \%
$$

Where $\mathrm{AWE}=$ average weed efficiency
The effective field capacity was determined from Equation (3) after weeding $3 \times 1.5 \mathrm{~m}$ (0.00045ha) within an average of $1 \mathrm{~min} 57 \mathrm{secs}$ ( 0.0325 hours) for both attachments. The time used for turning and adjustment was $10 \mathrm{sec}$ (0.00266hours):

$$
E F C=\frac{0.00045}{0.0325+0.00266}=0.0129 \mathrm{ha} / \mathrm{hr}
$$

The theoretical field capacity of the weeder was determined computing the rate of weeder coverage at its $100 \%$ rated width. Average width of cut of the three implements was $0.19 \mathrm{~m}$ (from Table 2) while the average speed of operation of the three implements 
was $1.008 \mathrm{~km} / \mathrm{h}$. Thus, from Equation (4), the theoretical field capacity was determined as:

$$
T F C=\frac{0.19 \times 1.008}{10}=0.019 \mathrm{ha} / \mathrm{h}
$$

The field efficiency of the weeder was computed from Equation (5) as:

$$
\eta_{e}=\frac{0.0129}{0.019} \times 100=67.9 \% \approx 68 \%
$$

The plant damage efficiency was calculated using Equation (2). After weeding three different rows of about $10 \mathrm{~m}$ length each, it was discovered that no plant was damaged by both attachments. This shows a $100 \%$ plant damage efficiency. Therefore, the plant damage efficiency is calculated thus;

$$
\text { Plant Damage }(\%)=\left(1-\frac{29}{29} \times 100\right)=0
$$

Conclusion: A single row hand-pushed mechanical weed control machine designed and developed. The machine is light in weight which makes it easy to be pushed with less effort, save time and energy and effective in its output. It is capable of promoting the living standard of peasant farmers by reducing the drudgery involved in weeding. The weed control machine has an efficiency of $68 \%$ with no plant damage during the weeding trials conducted. As can be assessed from Table 4, the average cost of the weeding machine is N21, 000:00.

Table 4. Bill of Engineering and Material Evaluation

\begin{tabular}{lllll}
\hline S/N & Description & Quantity & Rate(N) & Amount $(\mathbf{N})$ \\
\hline $\mathbf{1}$ & 3mm mild steel & Quarter length & - & 3500 \\
$\mathbf{2}$ & 5mm flat bar & One length & - & 3500 \\
$\mathbf{3}$ & Bolt and nut & 20 pieces & 50 & 1000 \\
$\mathbf{4}$ & 10 mm iron road & 0.75 of a length & 2000 & 1500 \\
$\mathbf{5}$ & Cutting disc & One disc & 1000 & 1000 \\
$\mathbf{6}$ & Electrode & Half pack & 1000 & 500 \\
$\mathbf{7}$ & 10 mm Bearing & Two & 250 & 500 \\
$\mathbf{8}$ & 30 mm Round pipe & One length & 2000 & 2000 \\
$\mathbf{9}$ & Pneumatic tyre & Complete set & 3000 & 3000 \\
$\mathbf{1 0}$ & Square road & Quarter length & 2000 & 500 \\
$\mathbf{1 1}$ & Paint & 1/3 gallon & & 500 \\
$\mathbf{1 2}$ & Transportation & - & & 500 \\
$\mathbf{1 3}$ & Miscellaneous & & 3000 \\
$\mathbf{1 4}$ & Total & & $\mathbf{2 1 0 0 0}$ \\
\hline
\end{tabular}

Acknowledgments: The authors would like to extend their gratitude and appreciation to the management of the Institute for Agricultural Research (IAR), Ahmadu Bello University, Zaria for providing fund required to carry out the study.

\section{REFERENCES}

Bisikwa, JD; Osiru, SO; Ogenga-Latigo, MW (1997). Timing of Hoe Weeding and Herbicide Application for Competitive Weed Control in Sorghum. $16^{\text {th }}$ East African Biennial Weed Sc. Conf. Proceedings. 205-214.

Chikoye, D; Schultz, S; Ekeleme, F (2004). Evaluation of Integrated Weed Management Practices for Maize in the Northern Guinea Savanna of Nigeria. Crop Protection. 23:895-900.

Chikoye, D; Ellis-Jones, J; Riches, C; Kanyomeka, L (2007). Weed management in Africa: experiences, challenges and opportunities. XVI International Plant Protection Congress.652653.
Dadari, SA; Mani, H (2005). The effect of postemergence weed control on irrigated wheat in the Sudan savannah of Nigeria. Crop Protec. J. 24: 842-847.

IFAD (1998). Agricultural Implements used by Women Farmers in Africa. Rome.

Ishaya, DB; Dadari, SA; Shebayan, JAY (2007). Evaluation of herbicides for weed control in sorghum (Sorghum bicolour) in Nigeria. Crop Protec. J. 26:1697-1701.

Johnson, DE (1995). Weed Management Strategies for Smallholder Rice Production. Brighton Crop Protec. Conf. on Weeds- 1995.1171-1180.

Kepner, RA; Bainer, R; Barger, EL (1978). Principles of Farm Machinery (3 edition), Avi Publishing Company Inc. Westport, Connecticut, USA.

Madhusudhana, S (2015), "Development of Double wheeled multipurpose weed remover" Intern. J. Eng. Tech. Manage. Appl. Sci. 3 (2) 349-4476 
Olowe, T; Dina, SO; Oladiran, AO; Olunuga, BA (1987). The control of weed, pest and disease complexes in cowpea (Vigna unguiculata (L.) Walp.) By the application of pesticides singly and in combination. Crop Protec. J. 6(4):222-225.

Tisdell, CA (1988). Economics of Weed Control on Public Conservation and Recreation Land: Assessing Costs and Benefits, Research Report or Occasional Paper No. 156, Department of Economics University of Newcastle.

Rana SS; Rana, MC (2016). Principles and Practices of Weed Management. Department of Agronomy, College of Agriculture, CSK Himachal Pradesh Krishi Vishvavidyalaya, Palampur, -125004, India.
Vissoh, PV; Gbehounou, G; Ahanchede, A; Kuyper, TW; Roling, N. (2004). Weeds as Agricultural Constraint to Farmers in Benin: Results of a Diagnostic Study. NJAS. 52(3/4):305-329.

Yadav, R; Pund, S (2007). Development and Ergonomic Evaluation of Manual Weeder Agric. Engineer. Inter: the CIGR E-Journal. IX. 